\author{
Srđan Teparić \\ University of Arts in Belgrade \\ Faculty of Music \\ Department of Music Theory
}

\title{
MOVEMENT STRATEGIES ASJ THE BASIS FOR CREATING TRANSCENDENCE IN THE COMPOSITION OF THE TREE OF LIFE BY IVANA STEFANOVIĆ ${ }^{1}$
}

\begin{abstract}
The composition The Tree of Life by Ivana Stefanović, for string orchestra, was written in 1997. It is composed of several entities of similar meaning, which derive from one motif. This fact alone suggests that this composition is essentially a powerful allegory that achieves a complex picture of the birth of human life and its development. The compositional techniques of decorating, superimposing and improvisation are powerful metaphors that indicate the flowering of living wood. From the analytical point of view, the composition by Ivana Stefanović is interesting to observe for it avoids postmodernist procedures. On the contrary, it is like reinterpreting the modernist idea of construction, but tying itself to the transcendent metaphor of life. The aforementioned procedures, which render their perpetual branching to be perceived as a single entity, lead to a com-

\footnotetext{
* Author contact information: teparic@gmail.com

1 This paper was presented at the 12th Biennial International Conference on Music Theory and Analysis held in Belgrade, 13-15 October 2017.
} 
plete musical gesture that begins, matures, and ends in transcendence. The common mode of all the procedures used in this piece is the movement that arises from one constant, a pulsation. Musical gestures related to several strategies will be examined in an analytical way. The first is decorating, which is directly related to similar strategies: growing, blooming and improvisation. The binding together of such situations leads to the creation of a unique musical gesture that points to life itself. Such symbolic unity, from the beginning to the end, has been realized in a transcendent mode. In this capacity, the composition The Tree of Life by Ivana Stefanović stands aside from most of the usual stylistic procedures of the time in which it was created. The combination of the strategies used points to a ludic game of linking the pulsation, that is, movements, which stand in direct union with the inexpressible sphere of symbolic, that is, unstoppable eternal currents.

The work deals with the analysis of strategies by which motor musical movements, as symbols, at the signifying level, are placed as gestures of expressing the transcendent. Moving lines and their collisions, places for creating prolongation, spreading and shrinking of the texture with the change of its layers, development of motifs with the pronounced application of the variation procedure, all these procedures will be treated as methods of building a unique tree of life. The composer began her narrative network with the basic motif cell, with the first statement, "in the beginning it was [...]". Based on the identification and method of combining the compositional strategies of the movement, it will be possible to prove the thesis of a transcendental musical gesture, formed as a result of the complex interrelations between the individual meaningful units.

Key words: movement, transcendence, gesture, transvaluation, opening, closing, stopping.

The composition The Tree of Life for String Orchestra by Ivana Stefanović, was written in 1997. Its form unambiguously points to the emergence of one whole from the other, and the basis of the entire development is the pulsating ostinato figure set at the very beginning of the work. It represents a constant in the course of the entire duration of the composition and in the allegoric meaning indicates a life pulse. Each of the parts of the form, branches off and flows (flowers) in several directions, so that the correct sense of that word, the form of this composition could be called a 'tree-like form'. The movement 'from birth to transcendence' is filled with signs that indicate the 'revival' of the musical piece. In this case, one could mention the existence of a work as a living, independent entity with a structure composed of signs that, in general, form the unique organism of this composition. Transcendental experience (from the Latin transcendere = to exceed, surpass) in this section could hardly be described literally. Transcendental in this composition, in a symbolic way is being reached by continuous melodic rises, constant tremolos and ostinatos referring to the world 'beyond', that is, on the author's tendency to present 'eternal unstoppable flows', as she 
has indicated herself. ${ }^{2}$ The process of the tree of life growing as the 'symbol of eternal renewal and new life' according to this idea should never cease, but it continues in eternity. The concept of transcendence is broadly defined in philosophy, and in the widest sense it implies what is an unsolvable problem for music analysis: transcendence is the passing of the limit of possible experience, it implies what is beyond senses or experience. Therefore, this term will be used in terms of an expressive genre, a narrative strategy that Robert S. Hatten used in his analyses. Such a strategy implies a change of state, and such a process of change, reaching the changed state in relation to the initial one, in the case of this composition, could be metaphorically called the narrative strategy 'from birth to transcendence'. ${ }^{3}$

Because of the specific psychological character of the signs that make up this composition, it might be most appropriate to call them gestures. ${ }^{4}$ By pointing to the psychologically meaningful features that the movement brings as the basic foundation of all events in the composition of The Tree of Life, we would tend to perceive this musical work as the metaphor of life. ${ }^{5}$

\footnotetext{
$2 \mathrm{http}: / /$ www.ivanastefanovic.com/index.php?lang=en\&nav=o_koncertima
}

3 Applying the idea of expressive genres (and this includes a frequent narrative strategy "from tragic to transcendent") to Beethoven's music, Robert Hatten explains the purpose of introducing this term in the following way: "Expressive genres serve to place interpretive activity in the proper realm. They are cued by basic oppositional features such as mode, high/middle/low style, texture, tempo, and thematic exploitation of familiar topics". Also, he speaks about nature of their appearance: "Expressive genres are tenacious, despite a necessary looseness in their definition. Since they could be viewed as archetypes that are invariant across a number of styles." Robert S. Hatten, Musical Meaning in Beethoven - Markendness, Correlation and Interpretation, Bloomington IN, Indiana University Press, 1994, 89 and 70.

4 The term is taken from Robert Hatten. Music gesture denotes the sign that would be analogous to the human gesture, but completely subordinate to the nature of music: "Gestures is generally defined as communicative (whether intended or not), expressive, shaping through time (including characteristic features of musicality as beat, rhythm, timing of exchanges, contour, intensity), regardless of medium (channel) or sensory-motor source (intermodal or cross-modal)". Robert S. Hatten, Musical Gestures, Topics and Tropes: Mozart, Beethoven, Schubert, Bloomington IN, Indiana University Press, 2004, 109.

5 This is what the composer herself says: "All instruments breathe in a common rhythm. Sometimes the rhythm slows down as a biological man sometimes slows down his breathing; sometimes it becomes upset and accelerates to some kind of culmination. All this is articulated by musical means, which include rhythm and pulsation. Rhythm, speed and occasional slowing are like a picture of a single branch. Then the image ceases a bit, the corona follows, a pause, and we observe the other branch, and the third one, so that eventually, we try to see the whole tree. [...] The tree of life is a symbol and much less description, and much more the idea that the eternal currents are unstoppable." Metamuzika - Ivana Stefanović: Drvo života, Radio televizija Srbije, Televizija Beograd, September, 2015. 
Below the surface level of the compositional methods, in the composition The Tree of Life musical gestures have been achieved which, in the deepest philosophical sense, indicate the sphere of flowering. Such a type of movement, displayed through a pronounced pulse, decoration and improvisation, is in constant contact with the sphere of the transcendental. What definitely represents the greatest methodological problem is how to connect any expressive genre, as well as transcendence, with the structural elements of the composition, that is, with the structural analysis that will be presented in this paper. ${ }^{6}$ As already mentioned, the form of this composition represents an upward arch, that is, each of the separated segments is an inseparable part of growth. The metaphorical 'treelike form' consists of sections that form part of an inseparable whole, but at the same time, they freely grow towards different sides, and each of the individual parts of the form could be called the leaf. It is quite obvious that the meaning in the context of the composition by Ivana Stefanović is expressed through simultaneous and successive relations between the parts of the form, thus creating a kind of narrative plane within the temporal structure. This phenomenon, which James Jakob Liszka calls transvaluation, is present in every musical work. ${ }^{7}$ In this case, it seems that all the perception of the listener is directed towards the movement and shaping of the ambiguous formal structure, which is at the same time an uninterrupted series and a form that branches off. However, the statement about a transvaluation process would be too banal if identical phenomena were not registered at a lower level. In fact, the composition The Tree of Life, represents a veritable network of the continuous flowering of motifs, their opening and closing. At the highest level of flowering, this phenomenon can be traced through a well-defined tonal plan, with an established line of wave-like dynamic motion that moves towards the last part of transcendence at the very end of the composition. At the lowest level, of the motifs, their constant growth occurs, that is, the upward movement, causing to the greatest extent the creation of the expectations of transfer to the level of the metaphysical.

The first thing to consider is the ratio of larger entities within the temporal range of the composition. (Example 1, scheme) The six sections in a row make

\footnotetext{
6 "Expressive genres are tenacious, despite a necessary looseness in their definition. Since they could be viewed as archetypes that are invariant across a number of styles." Robert S. Hatten, Beethoven - Markedness, Correlation and Interpretation, Indiana University Press, Bloomington\&Indianapolis, 1994, 70.

7 "The comprehension of sign translation in terms of rank and markedness is what I call transvaluation. In its most general form transvaluation is a rule-like semiosis which reevaluates the perceived, imagined, or conceived markedness and rank relation of referent as delimited by the rank and markedness of the system of its signals and the teleology of the sign user". James Jakob Liszka, The Semiotic of Myth: A Critical Study of the Symbol. Advances in Semiotics, Bloomington, IN, Indiana University Press, 1990, 71.
} 
up a common line. At the same time, they freely disperse outside the main line of the 'pulsation of life' - we even called the ostinato movement that runs through the whole composition by such a metaphor. The idea of a "tree-like form" with sections as leaves, is quite obvious. The composition (first section) begins with the aforementioned ostinato movement and ends with a pause based on an unresolved repetitive repetition (first section ends with a chord $d-f-a-c$ b. 32, second section with a chord $c$ major-f-g-g major- $b$, b. 44). Such pauses are also common in the subsequent flow and indicate the ending of branching off. The second and third sections (development and a new beginning) are the only two sections that complement one another. The third section ends with a pause on a small minor seventh chord from the tone $d$. At the end of the fourth section, there is also a chord stop on a small minor seventh chord made up from tone $e$.

Example 1: Ivana Stefanović, The Tree of Life, scheme of composition

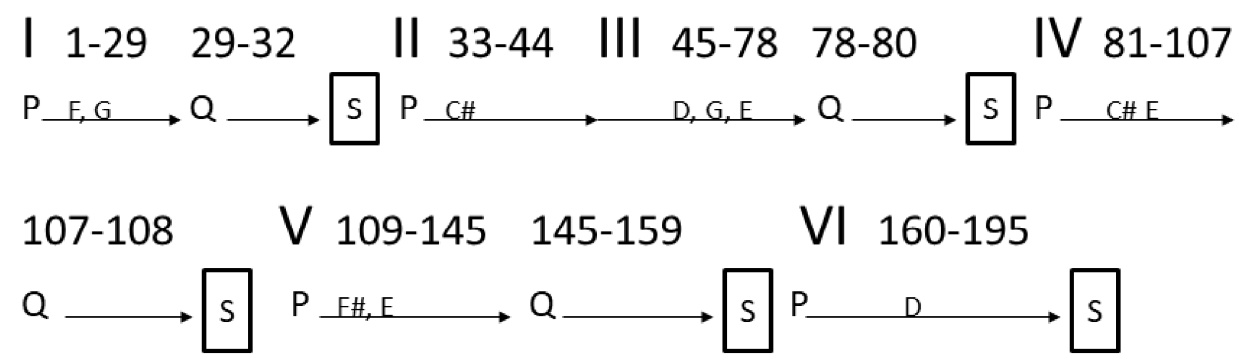

\section{Symbols:}

$$
\begin{aligned}
& \mathrm{P} \text {-prolongation } \mathrm{Q} \text {-quadence } \\
& \mathrm{S} \text { - stop }
\end{aligned}
$$

The tonal disposition in the first section of the composition, in $\mathrm{f}$ and in $\mathrm{g}$ (b. 15), points to the classical, and of course, re-textualized binary tonal opposition. Nevertheless, it is not conflicting in this work, but, in accordance with the supreme principle of the movement, the newly established tonality represents a temporary point in the context of all-round movement. It acts like a crossroads through which the branches of the tree are freely dispersed. The tonality of the second section is in c sharp, so that in a way this section 'would be resolved' into the tonality of the third section in d. In the middle part (b. 59) there is a 'conquering' of a new, 'higher' tonality in g, and from b. 67, a tonality in e. The apparent developmental potential of this segment results from the fact of tonal frequency. The fourth section, like the second one, starts with a tonality in c sharp, and ends with a tonality in e. The ascent towards transcendence, that is, 
the fifth section, begins with tonality in $\mathrm{f}$ sharp, and consequently there is again the tonality in e (b. 141). And finally, the last section brings the initial tonality in $\mathrm{d}$, but here one could not talk about reprise. The accelerated pace and linking to the previous flow, simply do not create such a psychological impression. So what does the briefly presented tonal plane tell us of the previous discussion? Apart from the fact that the treatment of tonal centres is adapted to the movement, at the same time it is obvious that frequent binary tonal oppositions within the section are in accordance with the principle of rise and fall, a wavy movement achieved on all planes. For this reason, the last section, as a dynamic peak of the whole composition (fortissimo dynamics), with an accelerated pace and a bright diatonic sound of chordal harmonies, is in fact a logical process of ending the global movement that runs like a backbone through the whole composition, but also a series of bifurcations achieved at the level of micro-motifs. The rehabilitation of tonality, a kind of neoclassical gesture, points to the influence of constructivist aesthetics, because it is the tonality that is the structural foundation, the solid point of the support on which the temporal structure of the composition itself lies. Such a modernist procedure is beyond the postmodernist concept of formal construction, and, on the other hand, it owes a great deal to the minimalistic aesthetics that all factors of construction are just reduced to the material itself. The postmodernism of Ivana Stefanović combines a neoclassical modernist idea with minimalist aesthetics, the most evident in the appearance of repetitive episodes of the work. In fact, postmodernism, in this case, takes on a modernist style, as it would otherwise have taken the vesture of Baroque, Classicism, or Romanticism.

A lower level of growing is associated with the motif. A very important gesture of reaching transcendence is the process of 'opening' or 'breathing', that is, the emergence of a critical chord that resolves upwards. Such a case, for the first time, occurs in b. 9-10 - where the minor sixth chord is resolved into the major six-four chord. (Example 2, b. 1-10) ${ }^{8}$ This 'bright' sound, in the context of observing the movement network throughout the composition, could be interpreted as a gesture of transcendence. Moreover, like breathing in, such a procedure seems to be the basic musical gesture of the composition, which indeed 'grows', at many levels. In other words, narration and the realization of meaning, in this part is achieved by the transvaluation of the motifs network composed of growing. In the full sense of the word, and not just in the allegorical meaning, the motifs network indicates breathing - it gives life to the whole musical piece in every way. As part of the above, the potential of the expressive genre of transcendence is reflected in the intensified phenomenon of consonances, thirds, fourths, fifths and sixths, these traditional intervals of construction of the triad.

${ }^{8}$ Sound examples are available online at the official New Sound YouTube channel. Please find the playlist here: https://youtu.be/6zowb0YQLm4 
A very good example of gradual opening is the second section (b. 33-44), in which by means of the regular intervals, by half-phrase, the opening strategy is implemented. (Example 3, b. 33-44) The first half-phrase brings a melodious leap within the fourth interval. In the next half-phrase there occurs a jump within the fifth interval. The next half-phrase, at a higher tonal height, brings again the jump of the fifth. After that, there occurs a feature in contradiction to this process - repetitivity, which in this composition always announces stopping in terms of quasi-cadencing. Opening-motion-breathing, repetitivity-cadencing and stopping, are the basic three strategies employed in this composition. These three models are implemented with constant changes, which allows opening at a higher level. The third section brings three varied wholes, with growths realized on a much broader scale than was the case in the previous section. (Example 4, b. 45-57) The first section (b. 45-57), as in the preceding flow, gradually grows through the $\mathrm{C}$-major scale, which additionally enhances the bright sound of the movement directed towards transcendence. The second section (b. 58-66) brings a tonal break in $\mathrm{g}$ and in $\mathrm{f}$ sharp, which in the perceptual sense points to a distortion of the straight-line directed flow, as well as to the general principle of variance - each statement is being repeated, but always slightly different from the previous one. The third section (b. 67-80), is finally interrupted by the occurrence of long chord sounds. The fourth unit (b. 81-108) brings an even broader range of harmonic-melodic-ostinato phrases. From b. 81 to b. 95,

Example 2: Ivana Stefanović, The Tree of Life, b. 1-10
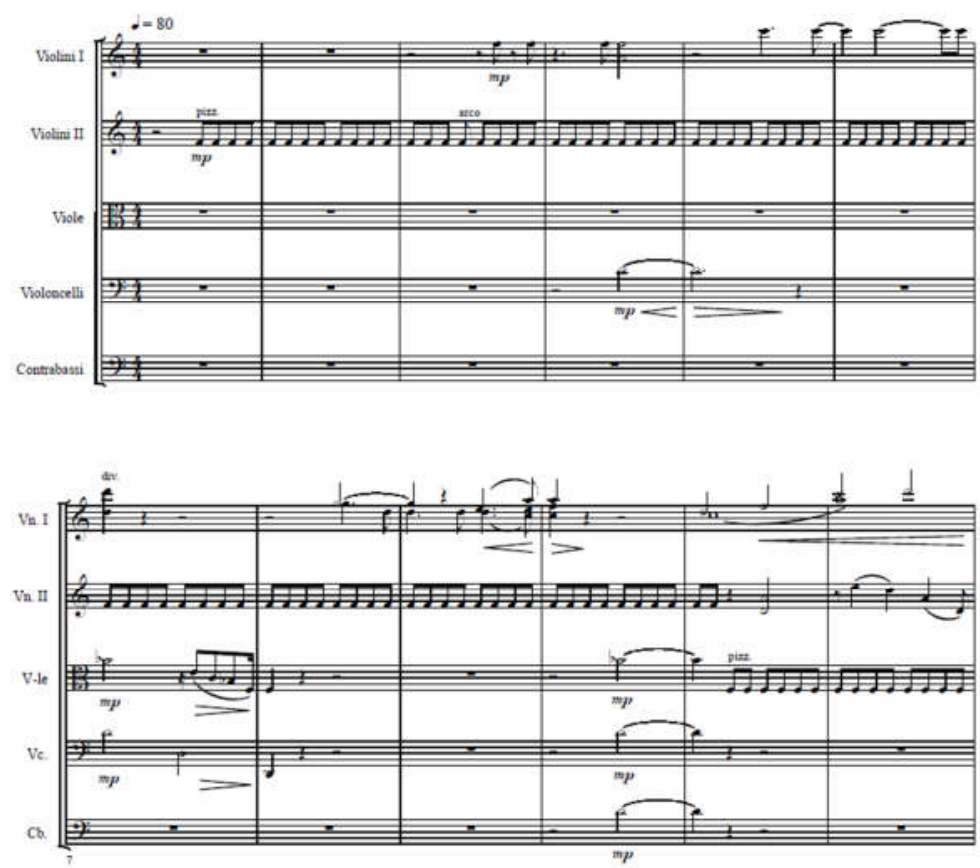
a phrase follows that is abruptly interrupted by the appearance of the repetitivity already described as quasi-cadencing (Example 5). This unit seems to have an external extension (b. 96-108), with the emergence of the widest quasi-cadencing in the flow up till now.

Example 3: Ivana Stefanović, The Tree of Life, b. 33-44
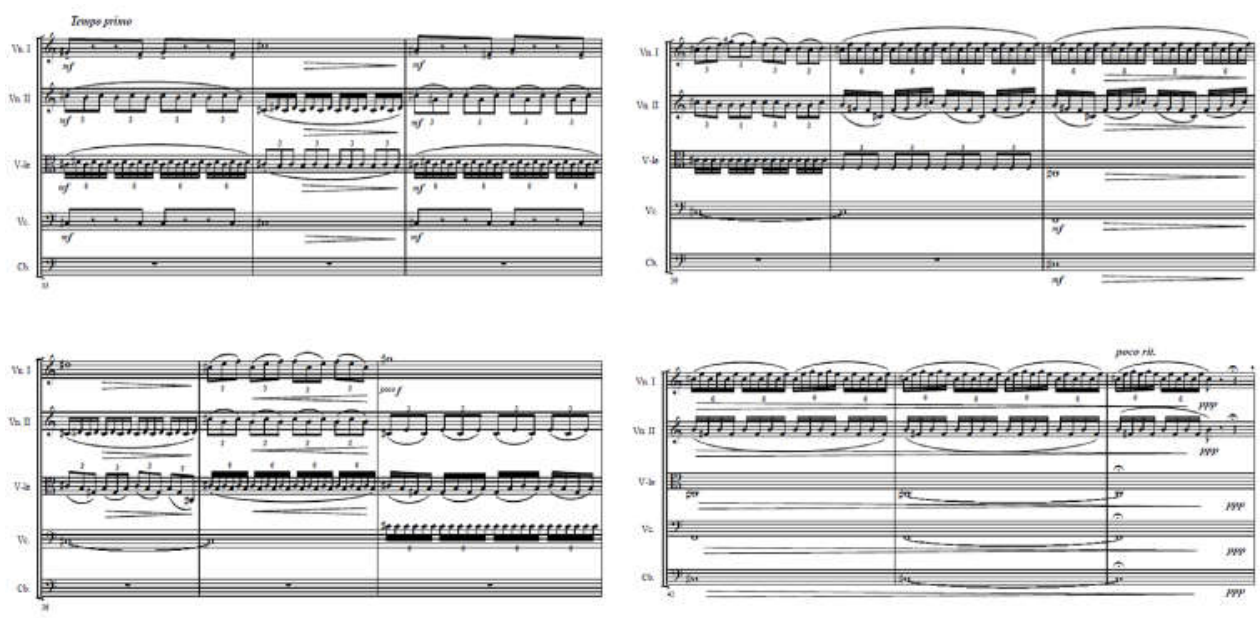

Example 4: Ivana Stefanović, The Tree of Life, b. 45-57
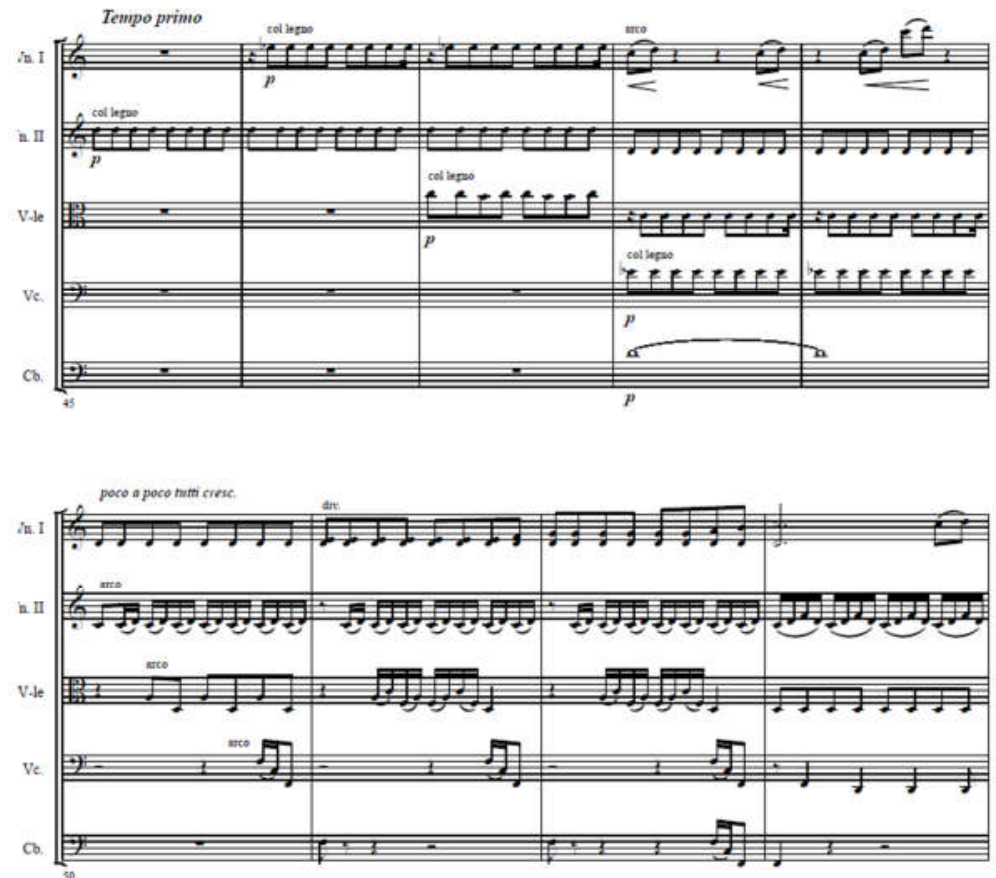
Example 4

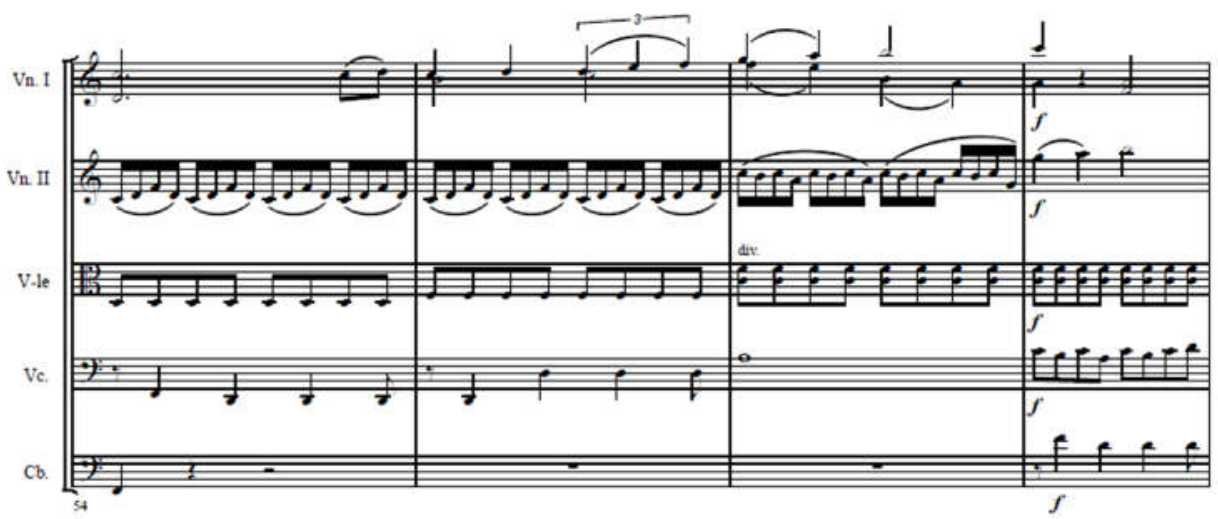

Example 5: Ivana Stefanović, The Tree of Life, b. 81-95
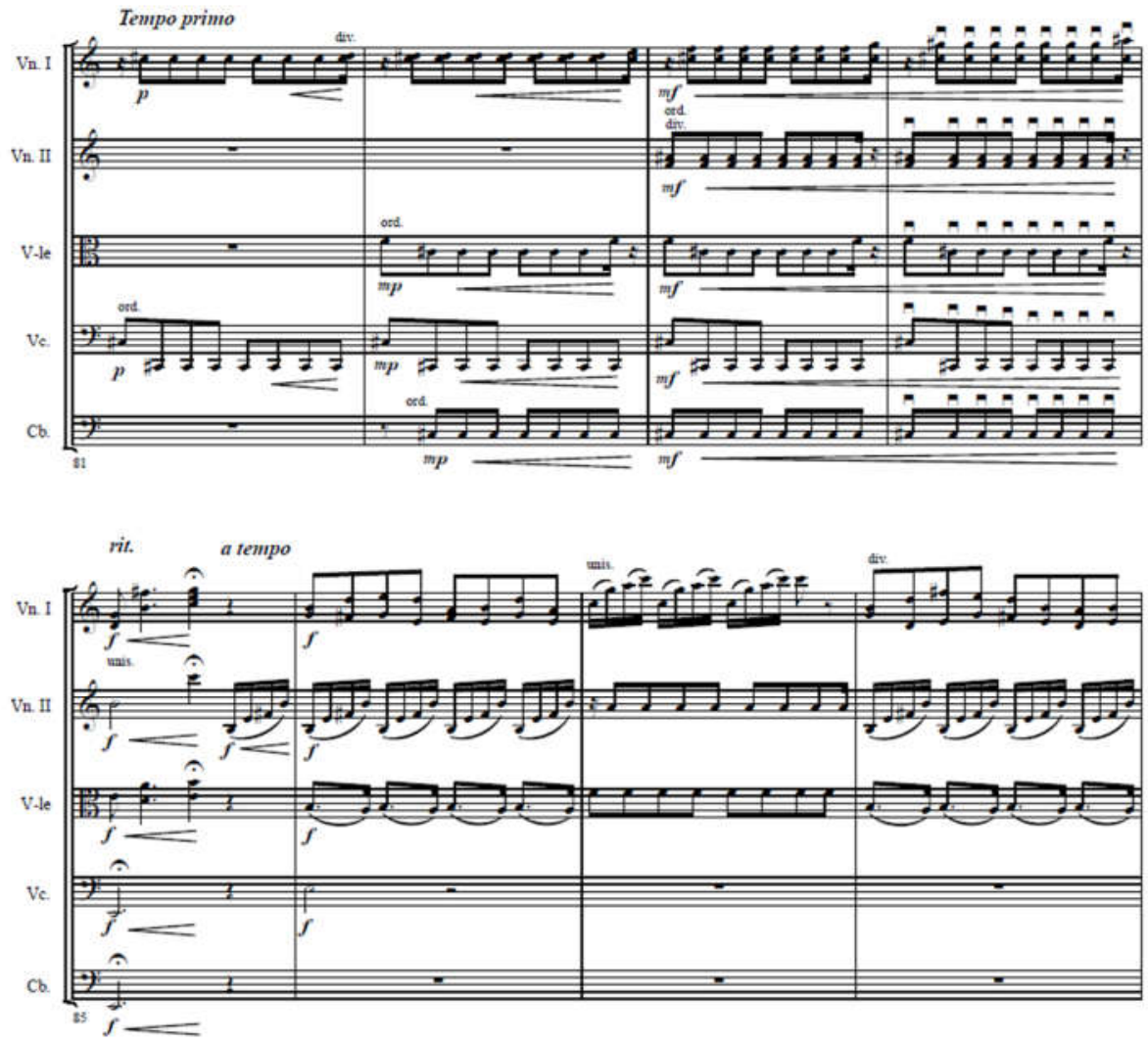


\section{Example 5}
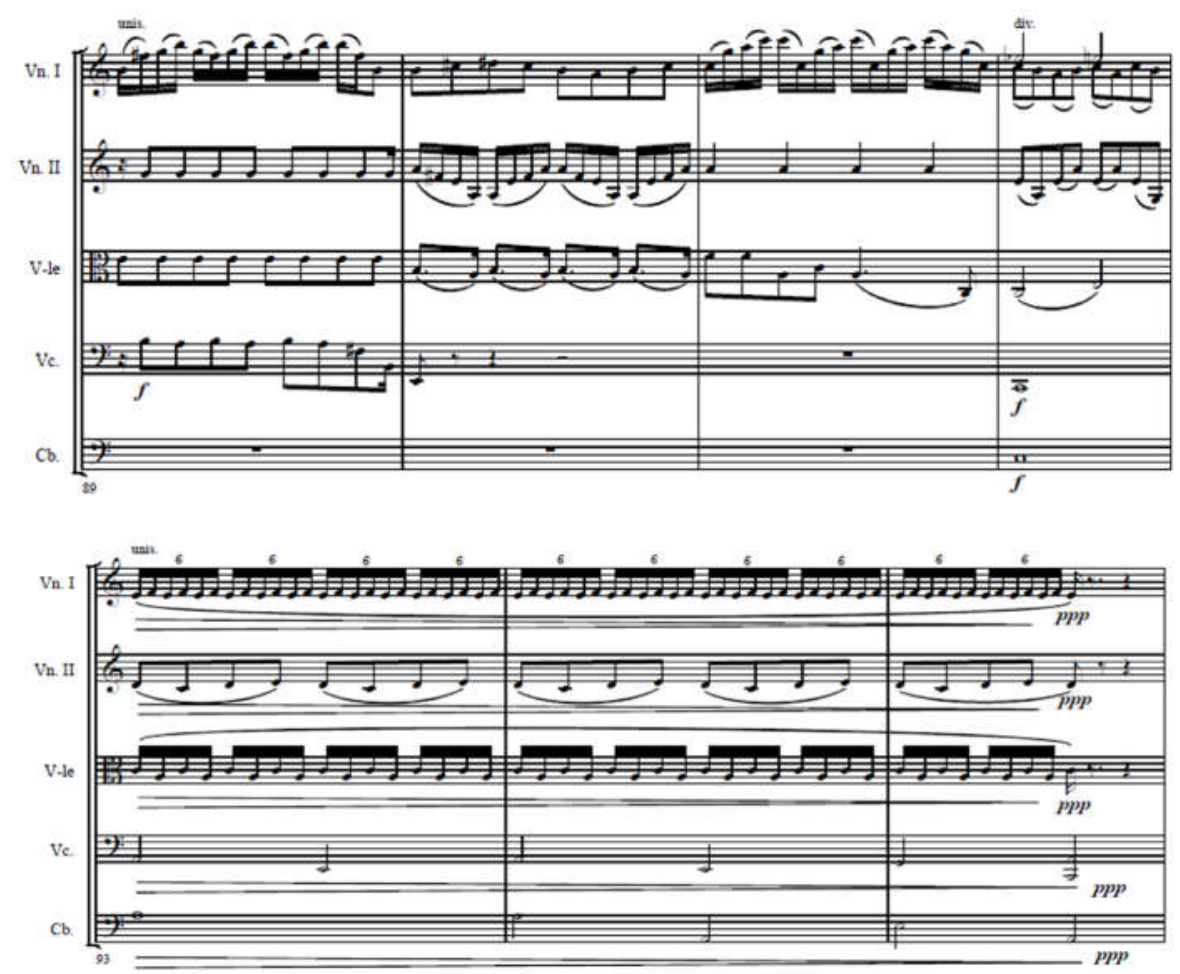

Another important strategy that ensures the smooth operation of the bloodstream of the composition is prolongation. Each of the beginnings in it possesses a strong potential for the emergence of the movement. In the first section it is the case of an occurrence of a regular ostinato eighth figure, upon which the intervals are gradually being upgraded. It is similar to the beginning of all other segments except the third. At the beginning of the third section there is a simulated sounding of a pulsating interval of the second between the sections of the second and the first violin, which in traditional sense is a typical form of tension generation. From this point, the tension ascends in a much wider plane than was the case in the previous, already described section. The entire fourth section (b. 109-159) represents the peak of the development process and the greatest form of opening expressed in the composition. The same is the case with closing, that is, quasi-cadencing, which within the unit gets the largest volume (b. 145-159). The last section, follows by acceleration of a regular ostinato figure that is with some exceptions given in the sounding of the tutti orchestra. It is most important for the realization of transcendence, that is, of process that we might call 
Teparić, Srđan: Movement Strategies as the Basis For Creating Transcendence in the...

'moving towards realization'. The final acceleration of the eighth pulse at the beginning of this section is followed by 'opening', this time given not through arpeggiated chords, but through a regular movement. (Example 6, b. 160-195) Thus, from b. 174-177 the melody moves in the range of the third, from b. 175 in the range of the fifth, octave, etc. The culmination occurs after an intensified repetition of fifth-octave harmony and stopping (b. 182-183). From b. 183, the occurrence of an e-minor triad that occasionally changes to seventh-chord or ninth-chord, actually results in the liberation of the accumulated energy of the movement that grew all the time (b. 183-189). At the very end, there follows a short and furious way of expressing the opening and closing strategies (b. 190195), for which we could say that is taking place 'on the other side', that is, after the release of the accumulated affect. The composition ends with a ninth-chord from the tone a, set in wide position.

Example 6: Ivana Stefanović, The Tree of Life, b. 160-195
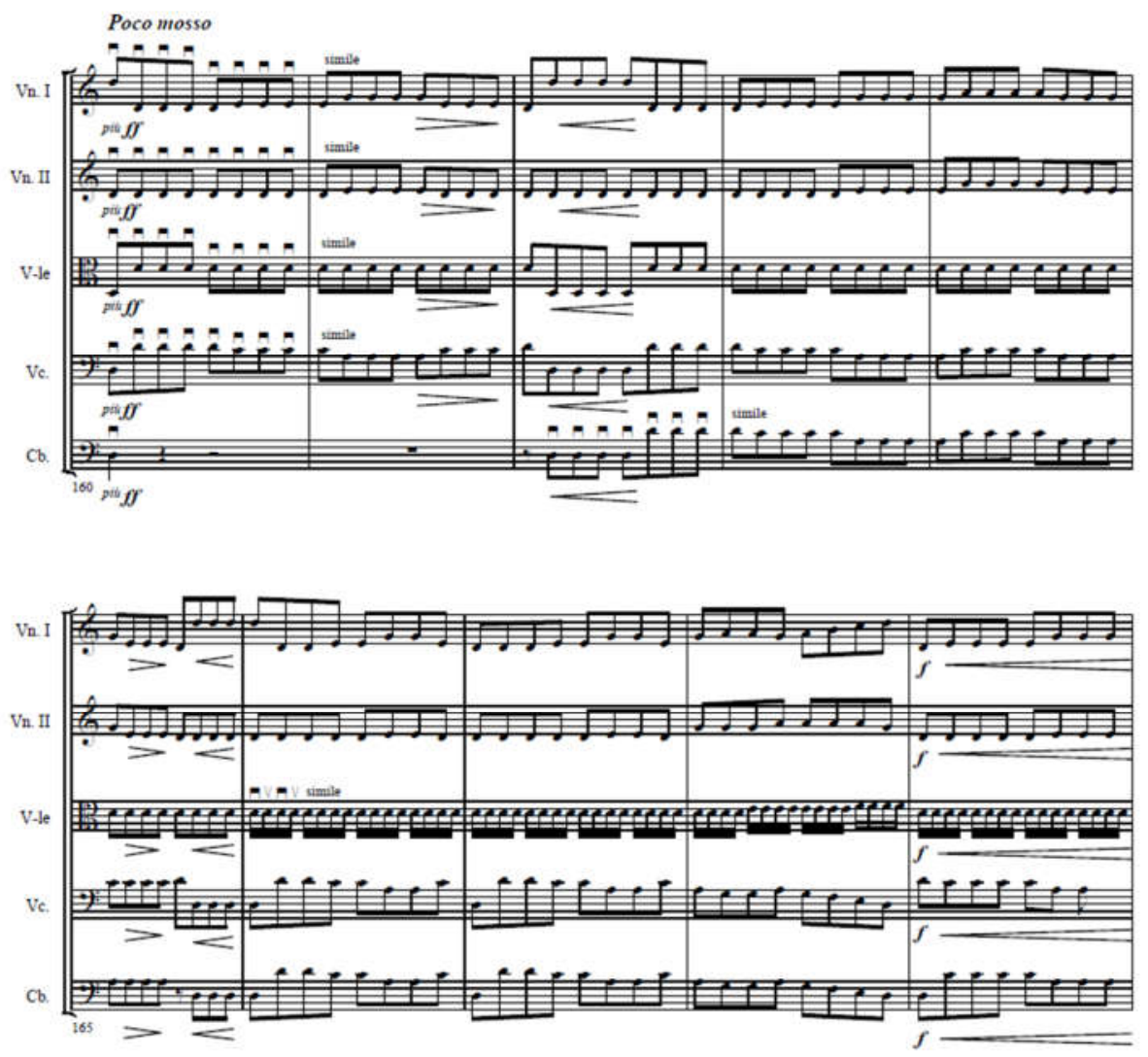


\section{Example 6}
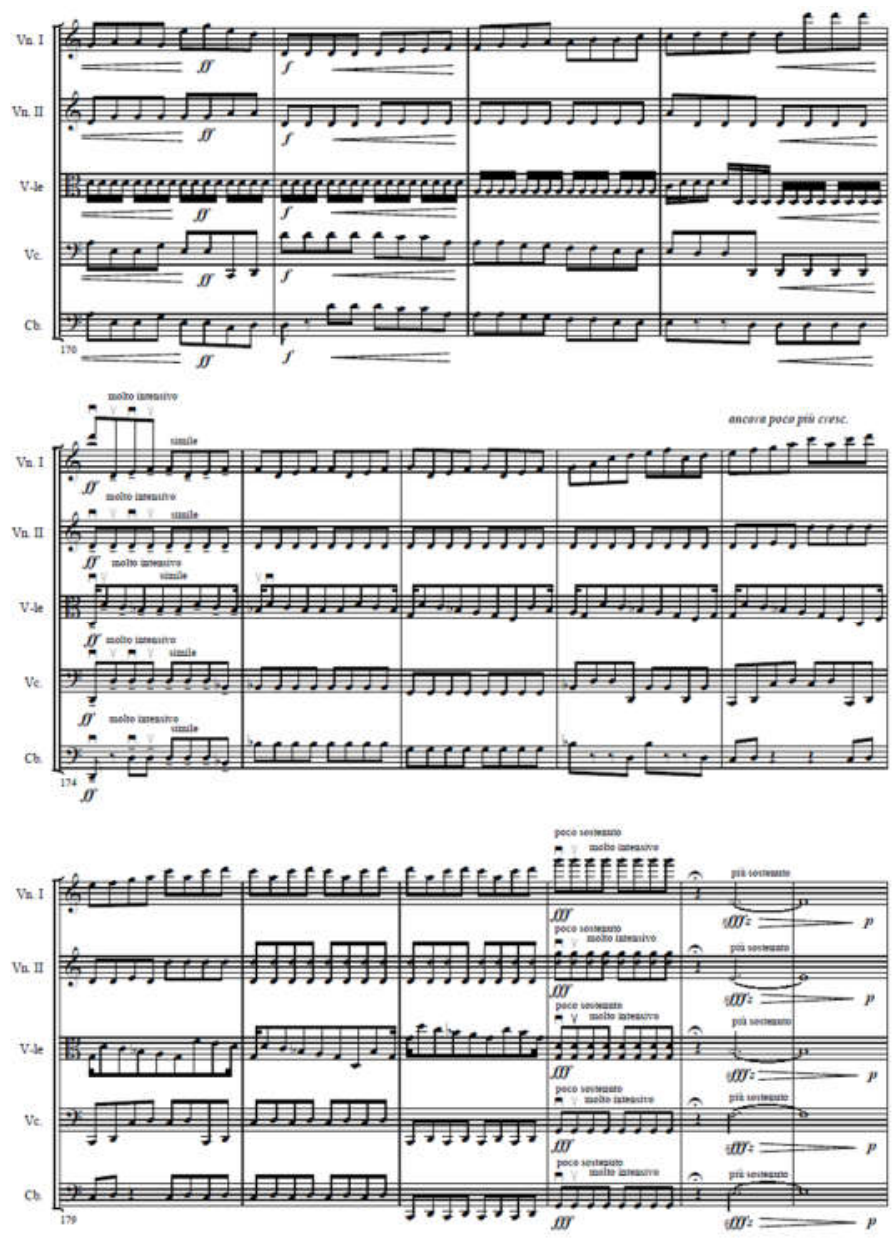

Finally, apart from the primary principle of variation and insistence on the principle of continuity, in accordance with the idea of branching, in some places we could still talk about the principle of discontinuity. In particular, this is the case with the relationship between the first and second sections - the second section, due to the previous stop and the appearance of a motif consisting of a second movement downwards and then a jump of a fifth upward, represents a possible binary model, which between the sections in the further flow is not present. A tendency towards the general movement upward, by moving the second interval downward, in this way is only momentarily called in question. The principle of contradiction against the principle of similarity, the hint of discon- 
Example 6 (end)
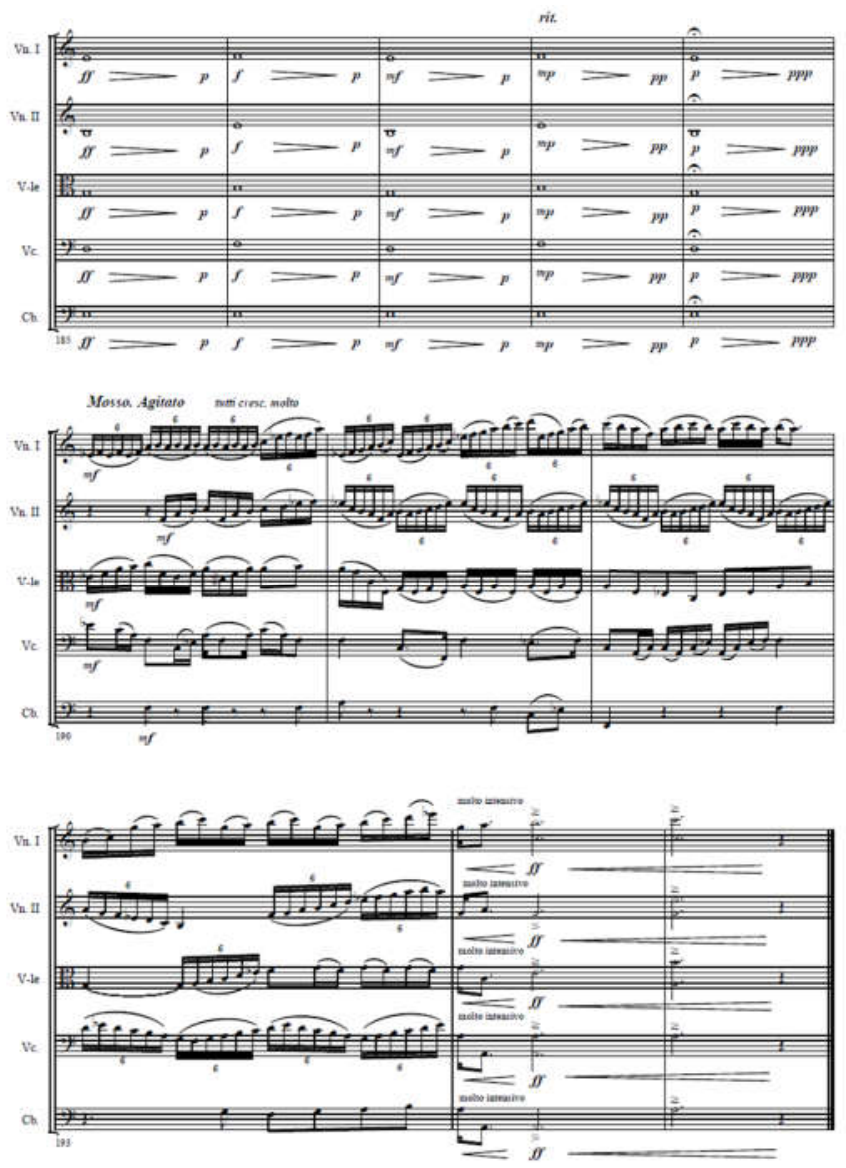

tinuity against the prevailing continuity, is part of the creation of a prolongation plane. ${ }^{9}$

9 The term prolongation certainly refers to Schenker: "As I said, the basis of a Schenkerian analysis is seeing music as directed motion in time, and for Schenker this was tied up with an almost metaphysical conception of music being a temporal unfolding of the overtone series which exists as simultaneity in all natural sounds. More specifically, Schenker saw music as a temporal unfolding, or prolongation of the major triad - the 'chord of nature', as he called it, since it exists as the first five partial of the overtone series, and which Schenker therefore saw as a specially privileged formation and indeed at the point of junction between what exists in nature as a simultaneity and what exists in art as a temporal process." In this case, it seemed convenient to use this term, although, of course, it would not be used in Schenkerian sense of the word. The prolongation will be understood as a principle or strategy, which designates 
As the directly opposed interval of a second extends the phrase to the opening, so in this case, meaningful opposing at a distance leads to a movement that, in the context of looking at the whole composition, nevertheless moves in the expected direction.

The composition by Ivana Stefanović explicitly shows what the basis should be for each relevant artwork. It is made from three existential principles of making an artwork. The principle of stability is what allows the breathing of the work itself. The development principle points to what happens during the process of growing and branching. And finally, the metaphysical principle points to the transcendental basis, and to that inexplicable part of the existence of every being. As we can see, this is the case with the existence of the very artistic work that, quite naturally, comes from the sphere of life, wherever it is in reality. When it comes to transcendence, a comparison with the epoch of Romanticism is inevitable. What makes transcendence in Romanticism special is the intensity whereby it is expressed. It is part and the final goal of narrative strategies and is achieved through the shift of various content spheres, as the crown and the ultimate outcome of all that the 'hero' had lived through until then. Contrary to this, transcendence with Ivana Stefanovic is embedded in the structure itself, it is a constructive, basic building element of the composition itself. In view of this fact, the moment of its final expression at the end is not so spectacular as to be the case in Romanticism, where it occurs after the presentation of various other content spheres. The 'opening' strategy points to a network of different levels of growing, and it is, like the breathing of a living being, a musical gesture that possesses a particle of life in itself that branches off in innumerable directions. If we could talk about avoiding postmodernist procedures, then in this fact we could have the main argument for such a claim. Transcendence in motion as a constructive, life-element of the composition is a principle that could be applied to a multitude of works in different epochs, whether compositions that develop from a single motif cell or, on the other hand, compositions based on the shifting of the affects, conditions or moods. What distinguishes the composition of Ivana Stefanović from such an eventual comparison is the fact that the idea of transcendence is not only indicated by the title, but through the principle of the opening-resolution it is entangled to the lowest level of the existence of the musical movement. With the use of a minimalist repetitive technique, inconsistently carried out and combined with free melodic movements, the composer managed to achieve a harmonic-melodic synthesis; moreover, the melody often

the impulses of the direction of movement at the start of each section of the composition. Nicholas Cook, A Guide to Musical Analysis, London \& Melbourne, J.M.Dent \& Sons LTD, $1987,39$. 
breaks up the vertical. The transvaluation of musical gestures that indicate opening, repetitivity and stopping in this sense, builds a complete set of logically distributed life-elements of this composition. For this reason, we could not speak about the stratified, the so-called postmodernist collages. On the other hand, The Tree of Life cannot even be classified in neoclassical homage, although there are the elements of stylistic imitation. Tonality, broken chords, consonance, all these traditional elements while using the repetition technique, however, are transformed. Transcendence through movement and through the combination of these elements and musical gestures, leads to the fact that the part of achieved spirit becomes an integral part of artistic poetics. It is shown here as a moving state that freely grows and branches. In all this, there is also a contradiction, since transcendence is carried out from one motif's cell, and in that sense, it is part of an archetype that originates from the originally pronounced syntagm "In the beginning was the word". The original word turned into a musical gesture, and then systematically implemented through the composition, is an aesthetic manifest which the composer herself explained as follows: "Everything starts and everything ends with an idea. Within the idea is only technique, technology, execution, skill, craft, but the idea is what matters." ${ }^{10}$ It is precisely through this idea that the composer Ivana Stefanović managed to emphasize the true nature of the unrepeatable encounter with the metaphysical world of the spirit.

\section{Summary}

The composition of The Tree of Life for String Orchestra by Ivana Stefanovic written in 1997, is composed of units that follow from one another. Each of the parts of the form branches off and flowers in several directions, so that the form of this composition we called 'tree-like form'. The basis of all development is the pulsating ostinato figure set at the very beginning of the work. It is constant during the entire duration of the composition and in the allegorical meaning indicates a life pulse. Movement from birth to transcendence is filled with gestures that indicate the 'revival' of the musical piece. In this sense, this work could also be considered as a metaphor of life, an independent entity with a structure composed of elements that in general form the unique organism of this composition. Below the surface level composed by compositional methods, in the composition The Tree of Life, musical gestures have been achieved which in the deepest philosophical sense point to the sphere of flowering. Such a type of movement, displayed through a pronounced pulse, decoration and improvisation, is in constant contact with the transcendent sphere. The potential of the expressive genre of transcendence is reflected in the intensified phenomenon of consonances, thirds, fourths, fifths and sixths, the traditional

10 Metamuzika - Ivana Stefanović Metamuzika - Ivana Stefanović: Drvo života, Radio televizija Srbije, Televizija Beograd, September, 2015. 
intervals of the construction of triads. Setting the motif, its growing and closing, is metaphorically comparable to the breathing process, and a network of such relationships in the composition is set from the smallest, motifs frame to the level of the larger wholes of the statement, and finally to the level of the composition as a whole. With the use of a minimalist repetitive technique, inconsistently carried out and combined with free melodic movements, the composer managed to achieve a harmonic-melodic synthesis. A network of set musical gestures of transcendence that points to opening, repetitivity and stopping, makes a complete set of logically arranged living elements of the composition. For this reason, we could not speak about the stratified contexts, the so-called postmodernist collages. On the other hand, The Tree of Life cannot even be classified into a neoclassical homage, although in it there are the elements of stylistic imitation. It seems, in fact, that the ostinato pulse and the initial motif, like the original syntagm "in the beginning there was a word" turned into a musical gesture and as such, were systematically carried out throughout the composition. Such transcendence achieved through the movement and the combination of the aforementioned musical gestures has led to the fact that reached part of the spirit becomes an integral part of the artistic poetics.

\section{Works cited}

Cook, Nicholas: A Guide to Musical Analysis. London \& Melbourne: J. M. Dent \& Sons LTD, 1987.

Hatten, Robert: Beethoven - Markedness, Correlation and Interpretation. Bloomington \&Indianapolis: Indiana University Press, 1994.

Hatten, Robert: Musical Gestures, Topics and Tropes: Mozart, Beethoven, Schubert. Bloomington, IN: Indiana University Press, 2004.

Liszka, James Jakob: The Semiotic of Myth: A Critical Study of the Symbol. Advances in Semiotics. Bloomington, IN: Indiana University Press, 1990.

Metamuzika - Ivana Stefanović: Drvo života. Radio televizija Srbije, Televizija Beograd, September, 2015. 